\title{
One Example of a Chemistry E-Lab Experiment: Chemical Equilibrium Reaction
}

\author{
http://dx.doi.org/10.3991/ijoe.v9iS8.3380 \\ Sérgio Leal ${ }^{1}$, João Paulo Leal ${ }^{2}$ \\ ${ }^{1}$ Universidade de Lisboa, Lisboa, Portugal \\ ${ }^{2}$ Universidade de Lisboa, Sacavém, Portugal
}

\begin{abstract}
In the last three years, e-lab, a real laboratory remotely controlled via the internet, has been an important educational resource in basic and secondary Portuguese schools in subjects like Physics and Chemistry. Since a pilot study performed in late 2009 that e-lab platform is being used in and outside the classroom contributing to increase students' motivation and interest toward scientific subjects. Currently, the e-lab team is interested in performing remote chemistry experiments, which are more difficult to execute in this kind of environment. At the present, the challenge is to create several chemistry experiments to use in e-lab. Here we explain one experiment focused in a chemical equilibrium reaction.
\end{abstract}

Index Terms - remote lab; chemistry; education; online laboratory; technology

\section{INTRODUCTION}

The e-lab platform is freely available at the following address: http://elab.ist.utl.pt/rec.web// and this remote laboratory located at Instituto Superior Técnico (IST) of Lisbon University is being used in Physics classes since 1999.

Ten years later e-lab was tested to evaluate if it would make sense to use the same platform in basic and secondary education. With that goal in mind, a pilot study resulting from a partnership between IST and the Portuguese Ministry of Education and Science was conducted in late 2009 with elementary and secondary school teachers. The results were very positive and from that time on until today the e-lab platform was applied in some classes looking for an increase in the performance and potential of the e-lab platform itself $[1,2]$.

In 2011 an usability upgrade for the actual interface (Fig. 1), more modern and intuitive, was performed.

One of the e-lab platform goals is to provide experiences that for monetary or safety reasons are not possible to accomplish in some schools. Until recently, Physics experiments were the only intended purpose since it is easier to make a remote experience in this field. However, since 2012 we have been studying various chemistry experiments that can be integrated in the platform. This communication deals presents the preliminary results of a chemical equilibrium reaction experiment, we have been working on.

\section{DESCRIPTION}

\section{A. First steps}

In the beginning of 2012, we started to integrate e-lab experiments outside IST, where all e-lab experiments are located until then. The first experiment outside IST was successful setup in a secondary school in Lisbon, Escola Secundária Padre António Vieira, with the help of some high school students (Fig. 2).

The experiment was duplicated from an already existing experiment in the e-lab platform, to allow the increase of simultaneous users, and the integration and duplication of experiments will continue in other schools and science museums for the next months.

After the completion of the first duplicate experiments outside the IST, we begun the research into new chemistry e-lab experiments.

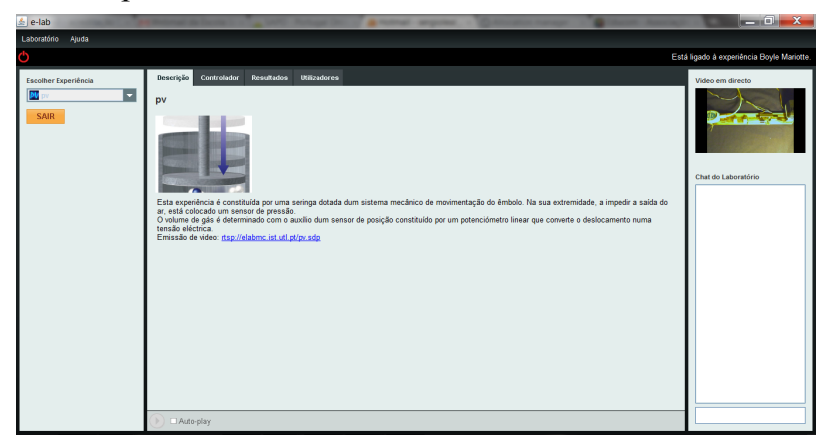

Figure 1. Present e-lab platform interface.

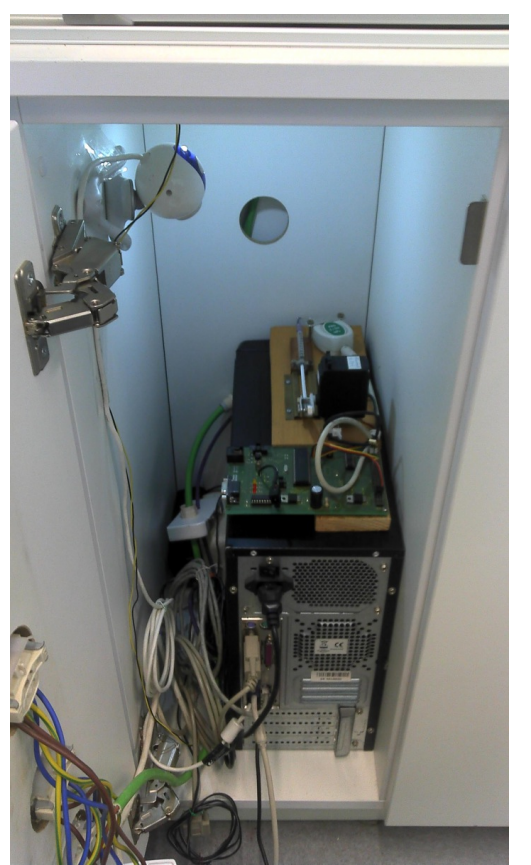

Figure 2. e-lab experiment duplicate at Escola Secundária Padre António Vieira, in Lisbon (Portugal). 


\section{B. Chemical equilibrium reaction}

There are several experiments currently under investigation in the field of Chemistry, one of them concerns on a chemical equilibrium [3]. This equilibrium was chosen because reaction path is associated with a distinctive color change, which is easily remotely followed. The mechanism of the involved reactions can generically be represented by:

$$
\begin{gathered}
\mathrm{CH}+\mathrm{OH} \rightleftharpoons \mathrm{C}^{-}+\mathrm{H}_{2} \mathrm{O} \\
\mathrm{O}_{2}+\mathrm{D} \rightarrow D_{o x} \text { (fast) } \\
D_{o x}+C^{-} \rightarrow X^{-}+D \text { (slow) }
\end{gathered}
$$

where $\mathrm{D}$ is the reduced (colorless) form of the dye methylene blue, $\mathrm{D}_{\mathrm{ox}}$ the oxidized form (blue), and $\mathrm{X}^{-}$ represents the oxidation products from the glucose, here represented as $\mathrm{CH}$.

Classically the reaction equilibrium is displaced by shacking a bottle half filled with a colorless liquid. After shacking the solution becomes blue due the dissolution of oxygen from the air in the solution and correspondent shifting of equation 2 above to the right. The reagents used in this case are an aqueous solution of sodium hydroxide, glucose and $1 \%$ methylene blue. Other possibilities of color changes can be achieved by using different acid/base indicator. We are very interested in the one using indigo instead of methylene blue, because it allows more than one color exchange.

\section{Method}

Laboratory tests were performed with methylene blue and indigo, the latter being more visually appealing (Fig. 3).

The quantities given are for one demonstration: $6 \mathrm{~g}$ of sodium hydroxide, $10 \mathrm{~g}$ of glucose, $4 \mathrm{~cm}^{3}$ of indigo carmine, $50 \mathrm{~cm}^{3}$ of ethanol, and $300 \mathrm{~cm}^{3}$ of water. None of the quantities is critical. In a $1 \mathrm{dm}^{3}$ conical flask put the sodium hydroxide, add the water and glucose and swirl until the solids are dissolved. Then add the indigo and shake the flask vigorously so that air dissolves in the solution [3].

The mixture will turn from yellow to red-brown with gentle shaking and to pale green with more vigorous shaking (Fig. 3).

To achieve the desired result, tests were performed manually stirring, using a magnetic stirrer and without stirring but using compressed air to increase the dissolved oxygen in the solution. In the context of a remote laboratory, using compressed air proved to be very effective and it seems the best option.

\section{Next steps}

At this stage, research lays in finding out: how many cycles are possible to perform reversibly; how long reactants can be kept active in a close system; which is the best container (close system) for use; which variables to measure and how, and which material is needed to build the experiment [4].

Currently, the previous steps are in the final analysis. After the needed value are obtained an experimental device will be assembled and tested in a remote environment.

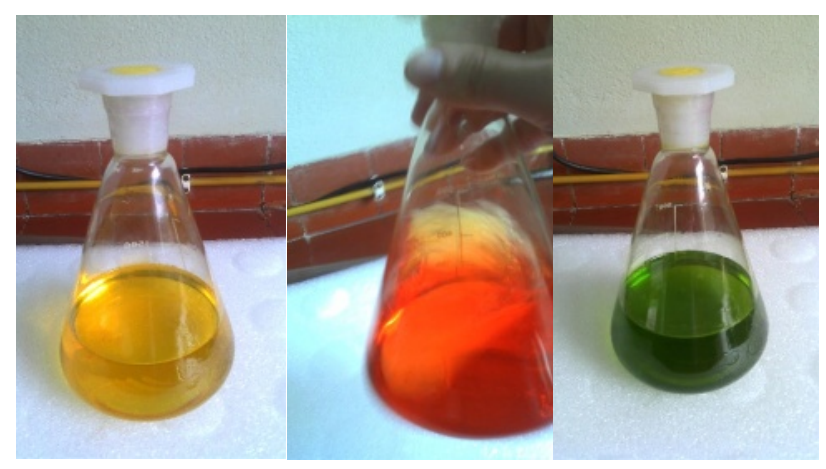

Figure 3. Demonstration of a chemical equilibrium reaction to be executed in the e-lab platform.

\section{CONCLUSION}

We have been creating experimental facilities via remote online laboratories that enable students and teachers to use real instruments, rather than simulations, to carry out experiments from anywhere at any time. Remote labs are different from simulations since the first allow students to conduct experiments in real time from their computer desktop [5].

With a webcam, students can observe the experiment in real time, control the parameters from their desktop, and download the data from the experiments to their computers.

The experimental nature of chemistry presents severe challenges for its teaching at distance. Many current online chemistry courses have no laboratory experience at all [6]. The e-lab platform has been shown to contribute to the teaching of scientific subjects like Chemistry and Physics from basic education to high school.

Given the predicted difficulties, the integration of chemistry experiments in the e-lab platform seems to be a great challenge. For now, research into this new experiment has progressed very positively and it is very likely that in the near future a new e-lab experiment dealing in real time with chemical equilibrium be available.

\section{ACKNOWLEDGMENT}

Sérgio Leal thanks a scholarship awarded $\mathrm{PhD}$ by Fundação para a Ciência e Tecnologia (SFRH/BD/ 44889/2008).

\section{REFERENCES}

[1] S. C. Leal, J. P. Leal and H. Fernandes, "E-lab: a valuale tool for teaching," Contemporary Issues in Education, vol. 1(2), pp. 167174, 2010.

[2] H. Fernandes, S. C, Leal and J. P. Leal, "E-lab: o laboratório online," Gazeta da Física, vol. 33(3), pp. 37-40, 2010.

[3] A. G. Cook, R. M. Tolliver and J. E. J. Williams, "The blue bottle experiment revisited," J. Chem. Ed., vol. 71(2), pp. 160-161, 1994. http://dx.doi.org/10.1021/ed071p160

[4] S. C. Leal, J. P. Leal and H. Fernandes, "Experiência e-lab: equilíbrio químico para o ensino da Química," unpublished.

[5] A. C. Hyder, "Design and implementation of remotely controlled laboratory experiments," M. S. thesis, Georgia Institute of Technology, The George W. Woodruff School of Mechanical Engineering, Georgia, 2010.

[6] F. A. Senese, C. Bender and J. Kile, "The internet chemistry set: web-based remote laboratories for distance education in chemistry,” IMEj J. Comput.-Enhanced Learning, vol. 2(2), 2000. 


\section{AUTHORS}

Sérgio Leal is with the Departamento de Química e Bioquímica, FCUL, Lisboa, Portugal, (e-mail: sergioleal20@gmail.com)

João Paulo Leal is with the Unidade de Ciências Química e Radiofarmacêuticas, ITN-IST, Sacavém, Portugal (e-mail: jpleal@ctn.ist.utl.pt

This article is an extended and modified version of a paper presented at the International Conference exp.at'13, held 18-20 September 2013, in Coimbra, Portugal. Submitted 18 November 2013. Published as resubmitted by the authors 04 December 2013. 